\title{
PEMBUATAN KREASI LAMPU HIAS DENGAN MEDIA BAMBU DI DESA JANTHO MAKMUR
}

\author{
Dedy Afriadi ${ }^{1}$, Saniman Andi Kafri ${ }^{2}$, Hariananda Pratama ${ }^{3}$ \\ Institut Seni Budaya Indonesia Aceh \\ e-mail: dedykalee@yahoo.co.id, saniman1992alas@gmail.com, harianandapratama@yahoo.com \\ Diterima : 14 Maret 2019. Disetujui : 9 Mei 2019. Dipublikasikan : 30 Juni 2019 \\ (C)2019 - DESKOVI Universitas Maarif Hasyim Latif. Ini adalah artikel dengan akses \\ terbuka di bawah lisensi CC BY 4.0 (https://creativecommons.org/licenses/by/4.0/)
}

\begin{abstract}
ABSTRAK
Jantho merupakan daerah dataran tinggi yang menjadi ibu kota Aceh Besar, kota Jantho menjadi pusat kota dan menjadi pusat administrasi untuk daerah Aceh Besar, meskipun kota Jantho menjadi kota, tetapi kota Jantho masih dominan dengan daerah perhutanan dan perbukitan. Kota Jantho memiliki sumber daya alam yang besar namun belum termanfaatkan secara maksimal oleh masyarakat dan pemerintah Aceh Besar. Melihat sumber daya alam yang besar menjadi ide dan daya tarik untuk mengolahnya sehingga dapat meningkatkan perekonomian daerah tersebut. Permasalahan yang ada di daerah Jantho adalah kurangnya pembinaan dalam pembuatan kerajinan. Dengan terselenggaranya pengabdian masyarakat diharapkan dapat menambah dan mengembangkan wawasan masyarakat untuk membuat karya yang memiliki nilai jual. Salah satu upaya yang ingin dikembangkan adalah membuat kerajinan lampu hias dengan media bambu, dikarenakan bambu merupakan bahan/ media yang mudah didapatkan di kota ini.
\end{abstract}

Kata kunci: Bambu, Lampu Hias

\begin{abstract}
Jantho is a highland area that became the capital of Aceh Besar, the city of Jantho became the center of the city and became the administrative center for the Aceh Besar area, even though became a city, but was still dominant with areas of forestry and hills. The city of Jantho has large natural resources but has not been utilized maximally by the community and the government of Aceh Besar. Seeing large natural resources becomes an idea and an attraction to process it so that it can improve the economy of the region. The problem in the Jantho area is the lack of guidance in making crafts. With the implementation of community service, it is expected to be able to add and develop people's insights to create works that have selling value. One effort to be developed is to make decorative lights with bamboo media, because bamboo is a material / medium that is easily available in this city. Keyword: Bamboo, Decorative Lights
\end{abstract}

\section{PENDAHULUAN}

Kota Jantho ialah kota sepi yang mayoritas masyarakatnya adalah pegawai yang memilih tidak menetap dan hanya ramai pada saat jam kerja saja. Kota Jantho adalah Ibu Kota dari Kabupaten Aceh Besar. Jarak yang harus ditempuh untuk menuju ke Kota Jantho adalah $14 \mathrm{~km}$ dari lintas Banda Aceh Medan, sedangkan dari Banda Aceh Ibu Kota Provinsi berjarak $50 \mathrm{~km}$. Kota Jantho terdiri dari 13 desa. Kecamatan Kota Jantho di Provinsi Aceh merupakan daerah yang dominan dengan hutan dan perbukitan. Kekayaan Kota Jantho tersebut tidak semua dapat dikelola dengan baik oleh masyarakat dan pemerintah Aceh Besar, beberapa daerah masih belum dapat memanfaatkan potensi alam dengan maksimal.

Desa Jantho Makmur tersebut memiliki potensi alam seperti bambu, kayu, lahan, tanah, dan pertanian. Didalam kawasan Jantho Makmur kebanyakan ibu- ibunya hanya menjadi ibu rumah tangga saja dan tidak mempunyai pekerjaan lain, hanya melakukan pekerjaan rumah dan pada saat sore hari mengaji bersama dan pada saat malam tidak ada kegiatan lain yang dilakukan. Tidak banyak pekerjaan yang ibu-ibu tersebut bisa lakukan, kekayaan alam yang ada disekitar belum bisa di manfaatkan dan diproses dengan baik.

Desa Jantho Makmur berdekatan dengan desa Teurebeh dan Buket Meusara serta sebagai jalan alternatif untuk mengakses ke Aceh Jaya. Mengembangkan potensi yang dimiliki tersebut membutuhkan faktor-faktor pendukung dalam pelaksanaanya agar masyarakat dapat memperdayakan industry kreatif yang 4akan berdampak bagus pada ekonomi masyarakat. Jalur pemasaran Kota Jantho berdekatan dengan pusat Ibu Kota Propinsi dan ramai diserbu oleh pejabat setempat, hal ini membuat pemasaran menjadi strategis. 
Kawasan Jantho Makmur merupakan kawasan yang memiliki potensi alam menguntungkan bagi masyarakat setempat, desa sasaran dalam program ini adalah Desa Jantho Makmur, Kecamatan Kota Jantho Kabupaten Aceh Besar Provinsi Aceh. Jarak Desa Jantho Makmur dengan Kota Banda Aceh sekitar 50 $\mathrm{km}$ dan dapat ditempuh kurang lebih $1 \frac{1}{2}$ jam menggunakan kendaraan roda dua atau roda empat. Jumlah penduduk di Desa Jantho Makmur lebih kurang 954 jiwa,yang terdiri dari 258 kepala keluarga. Latar belakang mata pencarian masyarakat Kota Jantho bagi laki-laki berprofesi sebagai Pegawai Negeri Sipil (PNS) dan bagi wanita berprofesi sebagai ibu rumah tangga, sedangkan pemuda/pemudi tidak memiliki aktifitas yang lainnya selain bersekolah. Atas alasan inilah kami berinisiatif untuk membentuk program guna menambah aktifitas untuk menghasilkan produk yang dapat memiliki nilai jual dan menambah kreatifitas masyarakat itu sendiri. Melihat sumber daya alam yang belum termanfaatkan secara maksimal menjadi kegelisahan bagi kami untuk mengoalah dan memanfaatkanya menjadi nilai tambah bagi masyarakat Jantho Makmur. Selain itu, sasaran lain yang ingin dicapai adalah menjadikan Jantho makmusr sebagai desa home industry sehingga dapan menjadi desa percontohan bagi desa lainya, sehingga menjadikan kota Jantho menjadi kota industi. Pada tahap awal ini media yang digunakan untuk pembuatan kerajinan lampu hias ini adalah bambu, dikarenakan material bambu merupakan maetial yang praktis dan masih mudah dijangkau. Prodak lampu hias dengan menggunakan material bambu ini akan didesain semenarik mungkin sehingga dapat diterima oleh pasar lokal dan nasional, target dari pemasaran ini adalah, rumah huni, hotel, café, dan tempat-tempat lainya. Terdapat beberapa hal yang harus dikembangkan untuk bisa menjadikan kota Jantho menjadi kota industri yaitu model pengembangan Gampong Jantho Makmur sebagai produsen souvenir dan cinderamata yang memiliki karakter identitas dan peningkatan pengetahuan dan ketrampilan masyarakat Desa Jantho Makmur dalan memanfaatkan potensi alam berupa media bambu. Tujuannya adalah menjadi terwujudnya modal pendampingan desa Jantho Makmur sebagai produsen kerajinan souvenir dan cinderamata yang memiliki karakter identitas khas Kabupaten Aceh Besar/ khas Aceh, meningkatkan keterampilan dan ketelatenan dalam membuat souvenir dan cinderamata khas Aceh bagi masyarakat Jantho Makmur, dan menjadikan kota Jantho sebagai kota industri (home industry) serta meningkatkan perekonomiaan masyarakat Jantho Makmur. Manfaat yang bisa didapat yaitu memberikan pengetahuan kepada masyarakat tentang pengolahan bambu, mewujudkan masyarakat yang produktif dan inovatif dalam menciptakan sebuah karya, dan melatih kreatifitas dari masyarakat sebagai sarana untuk mengembangkan bakat dan minat dibidang kesenian.

Sasaran penelitian ini adalah masyarakat dari kalangan orang tua sampai remaja di kota Jantho, agar masyarakat di desa Jantho Makmur memiliki peranan yang sangat besar terhadap perubahan dan perkembangan desa Jantho Makmur sendiri melalui kreatifitas dalam membudayakan seni dan tradisinya.

Tinjauan pustaka merupakan salah satu usaha peneliti untuk mencari data-data terkait pengolahan bambu sebagai lampu hias. Tinjauan pustaka ini juga dilakukan dibeberapa perpustakaan seperti di perpustakaan kampis ISBI Aceh, Perpustakaan Kota Jantho. Dari hasil studi pustaka yang dilakukan ditemukan 3 (tiga) buku yang berhubungan dengan pengolahan bambu. Dari ketiga buku ini bisa dijadikan sebagai acuan dalam mencari inivasi-inovasi baru dalam berkarya, khususnya karya seni yang menggunakan media bahan bambu. Buku-buku yang digunakan sebagai acuan dalam berkarya adalah buku "Bambu Untuk Rumah Modern" (2011), "Aneka Anyaman Bambu" (2005) dan buku "Kerajinan Dari Bambu" (2007) buku-buku ini membahas tentang pengolahan bambu.

\section{PEMBAHASAN}

\section{Identifikasi Masalah}

Masyarakat desa Gampong Jantho Makmur yang mayoritasnya tidak memiliki aktifitas tambahan (selain bekerja) dengan cara inilah mereka mengisi kegiatan harian mereka dengankegiatan yang bermanfaat menghasilkan desain produk yang memiliki nilai jual sehingga dapat membantu untuk meningkatkan prekonomian masyarakat setempat. Kegiatan ini juga ditujukan untuk melatih kemampuan masyarakat dalam mengolah sumber daya alam yang ada sehingga memiliki nilai jual. Produk yang akan dibuat adalah lampu hias yang sebagian besar dari bahan bambu

\section{Persiapan Alat dan Bahan}

Bahan utama dari kerajinan ini adalah bambu didapat secara mudah dari Desa Jantho.

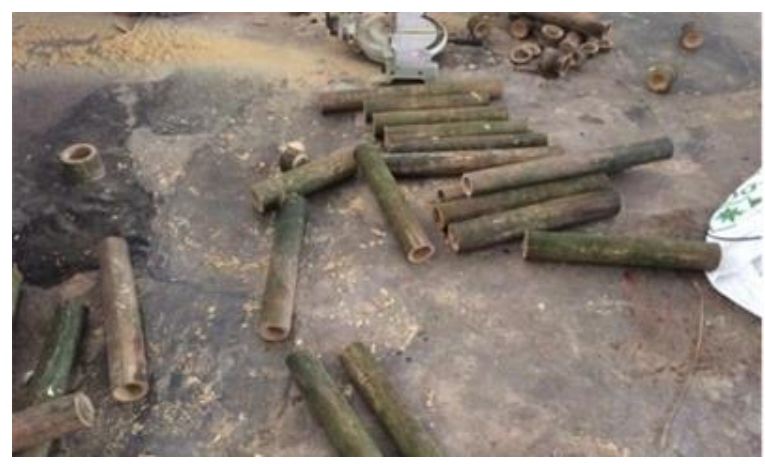

Gambar 1. Proses pengolahan bahan bambu ( Saniman Andi Kafri: 2018 ) 


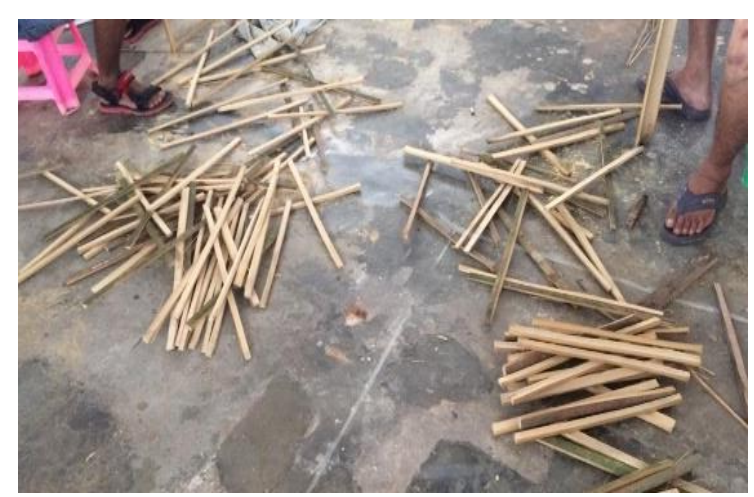

Gambar 2. Proses pengolahan bambu ( Hariananda Pratama: 2018 )

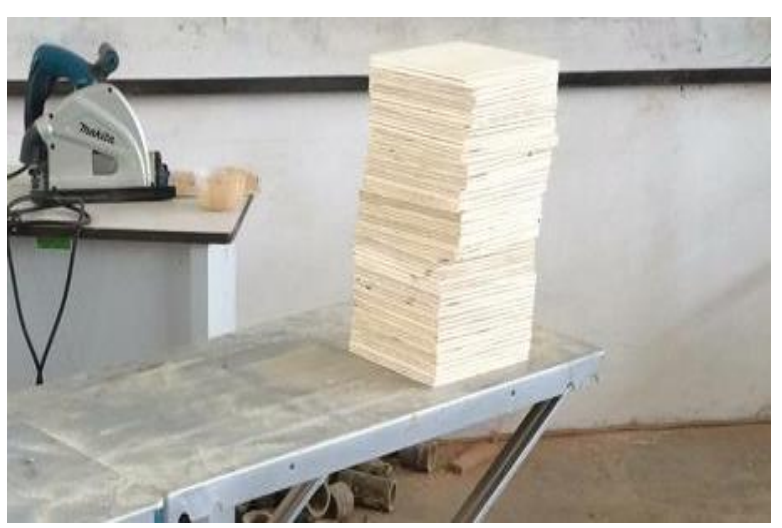

Gambar 3. Pengolahan triplek

( Hariananda Pratama: 2018 )

\section{Proses Pembuatan Lampu Hias}

Setelah bahan disiapkan, selanjutnya proses pembuatan lampu hias ini dimulai dari pemotongan bambu, perautan, penyusunan, pengecatan, dan finishing produk.

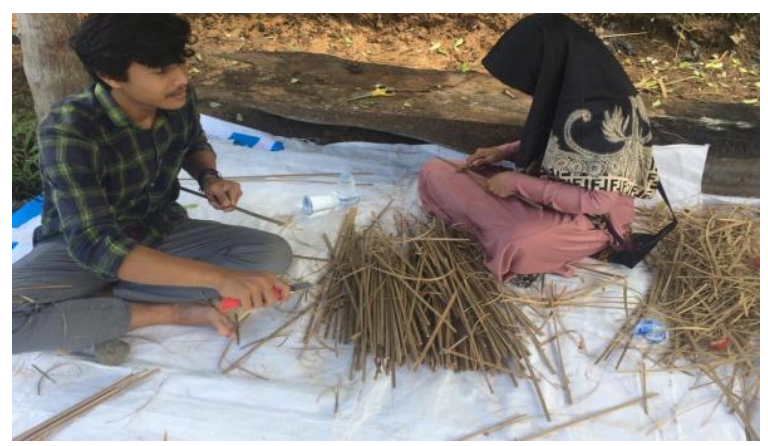

Gambar 4. Proses perautan bambu ( Saniman Andi Kafri: 2018)

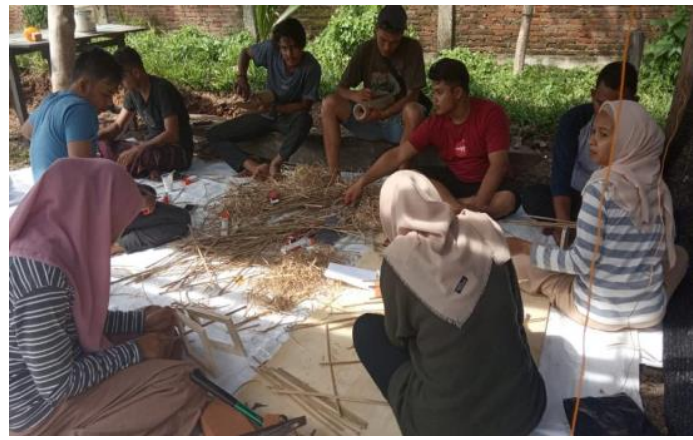

Gambar 5. Proses pembuatan kap lampu ( Iskandar: 2018 )

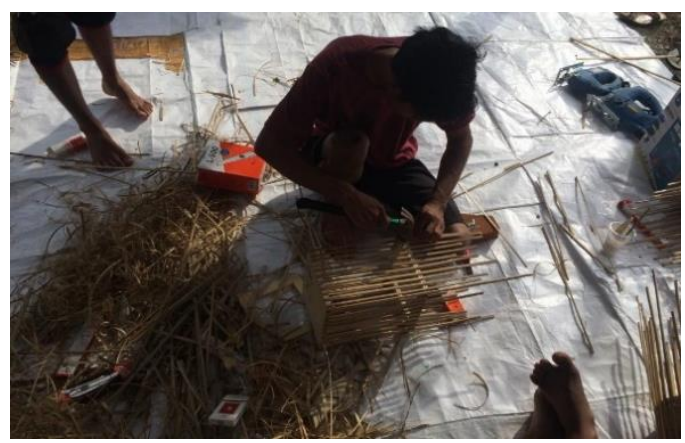

Gambar 6. Proses pembuatan kap lampu ( Iskandar: 2018 )

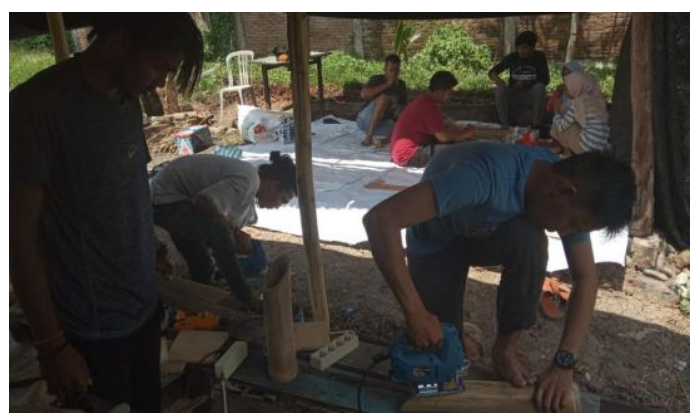

Gambar 7. Proses pembuatan kap lampu ( Iskandar: 2018 )

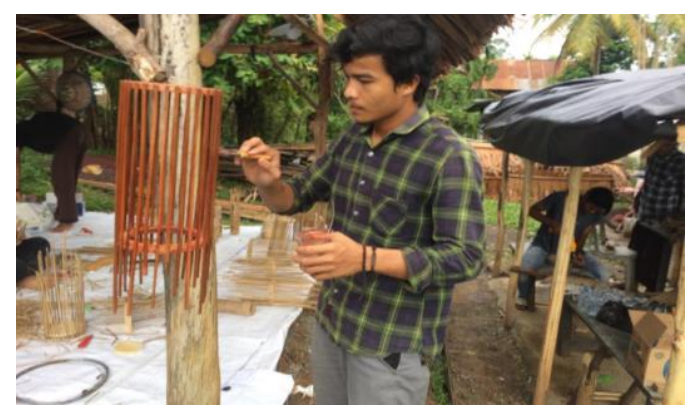

Gambar 8. Proses finishing kap lampu ( Saniman Andi Kafri: 2018 ) 


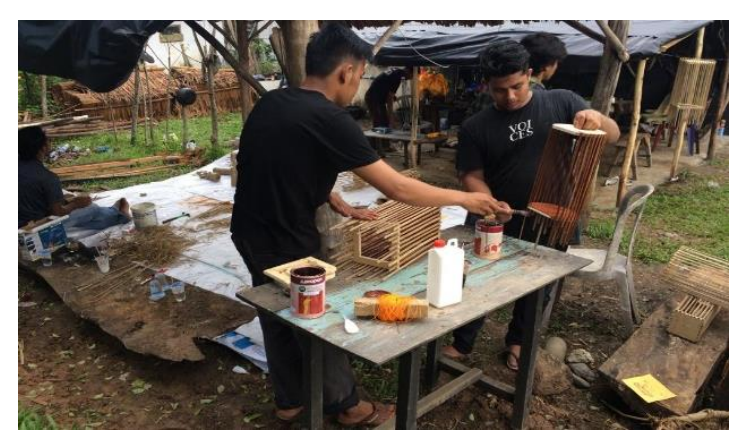

Gambar 9. Proses finishing kap lampu ( Iskandar: 2018 )

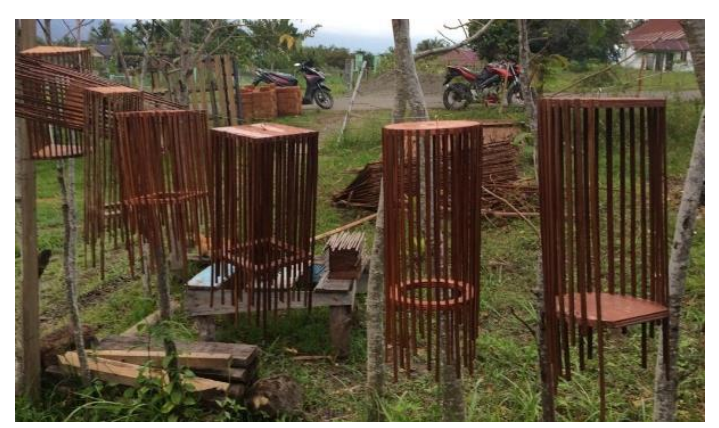

Gambar 10. Proses finishing kap lampu ( Saniman Andi Kafri: 2018 )

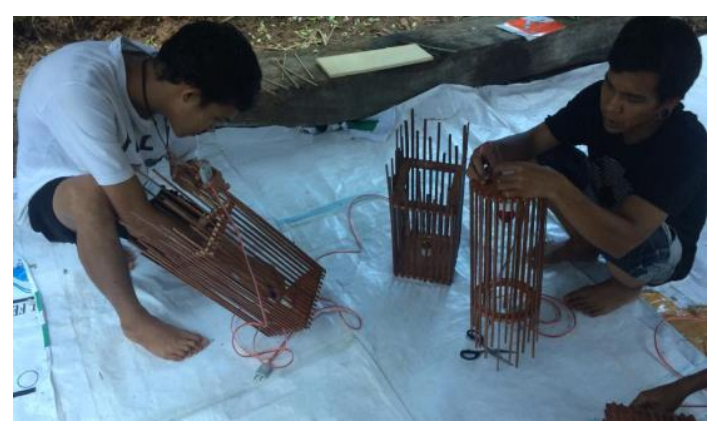

Gambar 11. Proses pemasangan lampu ( Saniman Andi Kafri: 2018 )

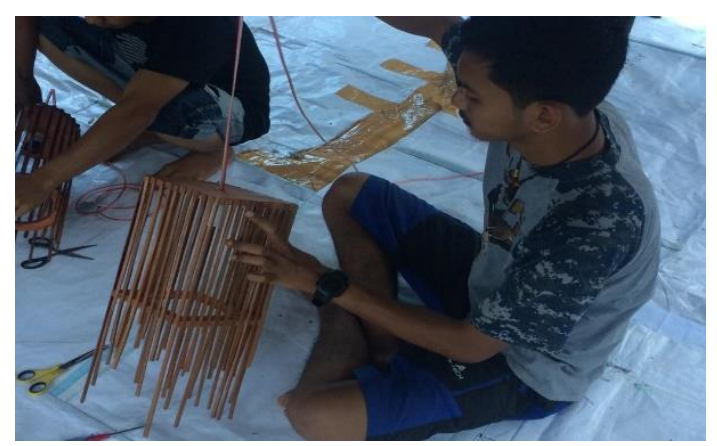

Gambar 12. Proses pemasangan lampu ( Saniman Andi Kafri: 2018 )

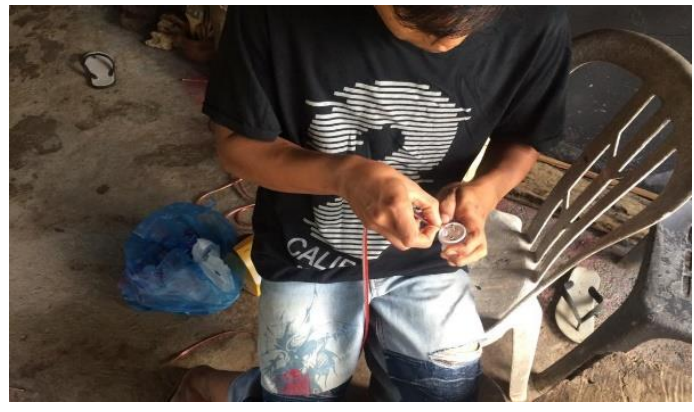

Gambar 13. Proses pemasangan lampu ( Saniman Andi Kafri: 2018 )

\section{Hasil Akhir.}

Setelah melalui proses produksi, maka lampu hias khas Desa Jantho bisa dipasarkan.

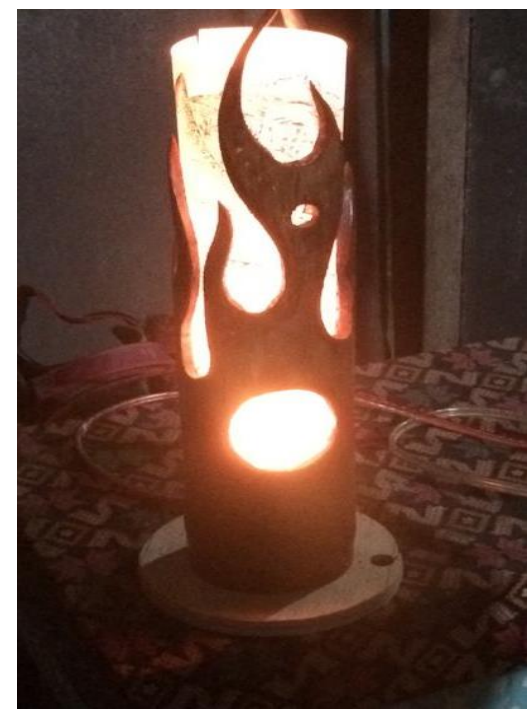

Gambar 14. Lampu Hias ( Saniman Andi Kafri: 2018 )

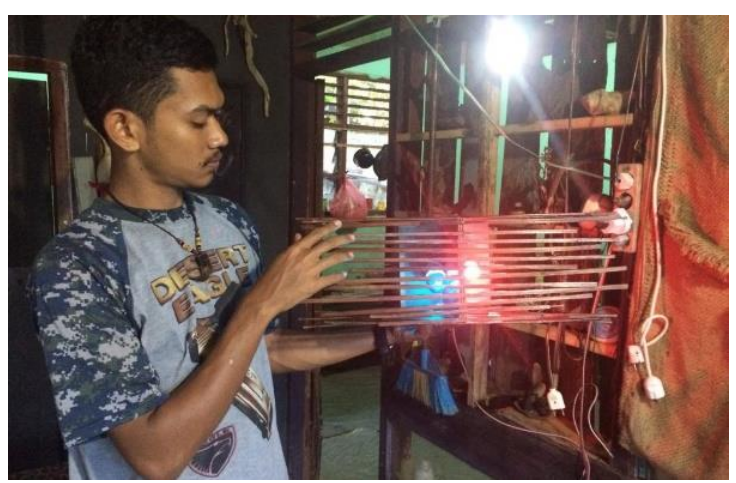

Gambar 15. Lampu hias ( Saniman Andi Kafri: 2018 ) 


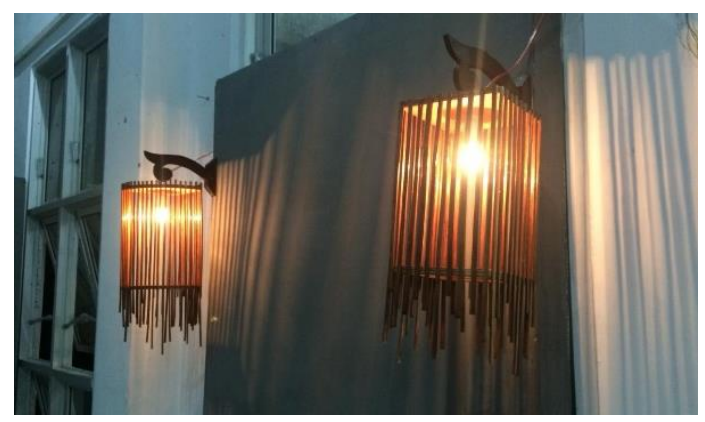

Gambar 16. Lampu Hias ( Saniman Andi Kafri: 2018 )

\section{KESIMPULAN}

Kota Jantho merupakan salah satu daerah yang kaya akan sumber daya alam, namun sangat disayangkan sumber daya alam ini belum termanfaatkan dengan baik. Sesuai dengan tri darma perguruan tinggi, salah satunya adalah pengabdian kepada masyarakat, ISBI Aceh sebagai lembaga pendidikan memiliki kewajiban dan tanggungjawab terhadap perkembangan kesenian yang ada di daerah Aceh dan sekitarnya, baik dibidang seni rupa maupun dibidang seni pertunjukanya.

Melalui Lembaga Penelitian Pengabdian Masyakat dan Penjaminan Mutu Pendidikan diharapkan dapat melahirkan karya-karya dengan konsep daerah setempat yang kemudian dikelola secara apik dalam bentuk tulisan maupun karya seni yang bermanfaat bagi penduduk setempat.

Pengabdian kepada masyarakat dengan judul "Pembuatan Kreasi Lampu Hias Dengan Media Bambu pada Desa Jantho Makmur" diharapkan menjadi salah satu bentuk kerjanyata yang dilaksanakan oleh lembaga Pendidikan yang ada, tidak hanya retorika semata. Selain itu pengabdian di kota Jantho Makmur ini juga diharapkan dapat menjadi kota industri yang bergerak dibidang souvenir, sekaligus menjadi desa binaan dan menjadi contoh untuk desa lainya.

Kota Jantho memiliki sumber daya alam yang besar,sangat disayangkan jika potensi alam ini tidak termanfaatkan dengan baik oleh masyarak. Diharapkan dengan adanya pengabdian ini bisa memacu motivasi masyarakat untuk berkreasi dan berkarya, sekaligus bisa meningkatkan perekonomian masyarakat sekitarnya. Saran kepada pemerintah daerah dan lembaga pendidikan seni, melalui tulisan ini agar selalu bekerja sama dengan masyarakat dalam mengembangkan potensi usaha industri yang sudah dibina.

\section{DAFTAR PUSTAKA}

Akmal Imelda, dkk, 2011, Bambu Untuk Rumah Modern, PT Gramedia Pustaka, Jakarta.

Gerbono Anton, Abbas Siregar Djarijah, 2005, Aneka Anyaman Bambu, Kanesius, Yoyakarta

Novari Eti, Sri Suparmi, 2007, Kerajinan Dari Bambu, Tiara Aksa, Surabaya.

Kartika Sony Darsono, 2007, Estetika, Rekayasa Sain, Bandung.

Kartika Sony Darsono, 2016, Kreasi Artistik, Citra Sain, Bandung.

Kumsatun, 2002, Ragam Hias dan Motif Aceh, Dekranas provinsi Nangro Aceh Darussalam. 
Dedy Afriadi, dkk / DESKOVI : Art and Design Journal, Vol. 2, No.1, Juni 2019, 21-26

(Halaman ini sengaja dikosongkan) 